\title{
Changes in axial length and choroidal thickness after intraocular pressure reduction resulting from trabeculectomy
}

This article was published in the following Dove Press journal:

Clinical Ophthalmology

12 June 2013

Number of times this article has been viewed

\author{
Shinichi Usuil ${ }^{1,2}$ \\ Yasushi Ikuno ${ }^{2}$ \\ Sato Uematsu' \\ Yuko Morimoto' \\ Yoshiaki Yasuno ${ }^{3}$ \\ Yasumasa Otori' \\ 'National Hospital Organization, \\ Osaka National Hospital, Osaka, \\ Japan; '2Department of Ophthalmology, \\ Osaka University Graduate School \\ of Medicine, Suita, Japan; \\ ${ }^{3}$ Computational Optics Group, \\ University of Tsukuba, Tsukuba, Japan
}

Correspondence: Shinichi Usui Department of Ophthalmology E7, Osaka University Graduate School of Medicine, 2-2 Yamadaoka, Suita, Osaka 565-087I, Japan

Tel +81668793456

Fax +8I 668793458

Email susui@ophthal.med.osaka-u.ac.jp
Purpose: To evaluate changes in axial length and choroidal thickness after trabeculectomy.

Patients and methods: Fourteen patients under 80 years of age with glaucoma, were enrolled. The choroid was imaged using prototypical high-penetration optic coherence tomography (OCT) and the thickness was measured. Axial length, choroidal thickness, and intraocular pressure (IOP) were measured bilaterally at $3 \mathrm{pm} 1$ day before and 6 days after trabeculectomy. The choroidal thickness was measured at the fovea and four other locations ( $2 \mathrm{~mm}$ superior, temporal, inferior, and nasal to the center of the optic nerve head).

Results: The IOP and axial length significantly decreased in eyes that underwent trabeculectomy ( $P<0.0001$ for the IOP; $P<0.001$ for axial length comparisons). The mean choroidal thicknesses significantly increased in eyes that underwent trabeculectomy compared to preoperatively ( $P<0.0001$ for the fovea; $P<0.01$ for four locations around the optic disc). The mean magnitude of change in IOP was correlated positively with the mean magnitude of change in axial length, but not correlated with the mean magnitude of change in choroidal thickness at the fovea that underwent trabeculectomy. The sum of the axial length and subfoveal choroidal thickness in eyes decreased significantly postoperatively $(P<0.05)$.

Conclusion: The axial length shortened, the choroid thickened, and the sum of the axial length and subfoveal choroidal thickness decreased with IOP reduction early after trabeculectomy.

Keywords: choroidal thickness, trabeculectomy, optical coherence tomography, IOP reduction

\section{Introduction}

Diurnal variations in intraocular pressure (IOP) and axial length have been reported, ${ }^{1-5}$ and some authors have reported a positive association between them. ${ }^{4,5}$ An experimental study also suggested that the axial length can be modulated by choroidal thickness changes that push or pull the retina in the chicken's eye. ${ }^{6}$ Some investigators have reported diurnal variations in choroidal thickness $s^{2,7,8}$ and a negative association between axial length and choroidal thickness in human eyes. ${ }^{5}$

It is important to explore the relationship between IOP and axial length to clarify the pathology of glaucoma. The Tajimi Study, a population-based study of Japanese subjects, found that myopia was a significant risk factor for development of openangle glaucoma. ${ }^{9}$ Other groups have reported similar results. ${ }^{10-12}$ The choroid is also an important tissue involved in the pathology of glaucoma. Duijm et al reported that choroidal circulation in normal tension glaucoma was slower than in control subjects. ${ }^{13}$ Some investigators have reported recently that the choroidal thickness in normal 
tension glaucoma is significantly thinner, at least in specific locations, than in normal subjects. ${ }^{14-16}$

Trabeculectomy, the gold standard filtering surgery for reducing IOP, causes morphologic changes in the ocular shape. Several studies have reported that the axial length decreases with reductions in IOP after trabeculectomy. ${ }^{17-20}$ However, the changes in the choroidal thickness after trabeculectomy are not clear.

In the current study, we investigated the changes in the IOP, axial length, and choroidal thickness after trabeculectomy and their association using high-penetration optical coherence tomography (OCT).

\section{Patients and methods}

\section{Patients}

The current prospective study included 14 patients with glaucoma who had undergone trabeculectomy at Osaka National Hospital. Two glaucoma specialists (Y Otori, $\mathrm{S}$ Usui) diagnosed glaucoma in these patients who were receiving maximal antiglaucoma medication. The inclusion criteria were previous cataract surgery (five eyes), previous trabeculectomy (one eye), previous trabeculotomy (one eye), simultaneous cataract surgery for age-related cataract (five eyes), laser suture lysis after trabeculectomy, and secondary glaucoma including uveitis and exfoliative glaucoma. Three patients had previously received trabeculectomy in fellow eyes. The exclusion criteria were an age of more than 80 years, the presence of neovascular glaucoma, and the complications of hypotony, such as maculopathy, choroidal effusion, choroidal hemorrhage, and expulsive hemorrhage after trabeculectomy.

The choroidal thickness, axial length, and IOP were measured bilaterally at $3 \mathrm{pm}$ the day before and 6 days after trabeculectomy. A prototype high-penetration OCT instrument was used to image the choroid and to measure the choroidal thickness at the fovea and the peripapillary area. Three masked examiners measured the choroidal thickness. The institutional review board of Osaka National Hospital approved the use of the prototype high-penetration OCT. All patients provided informed consent. The research adhered to the tenets of the Declaration of Helsinki, 1964.

\section{Prototype 1060 nanometer high-penetration OCT}

The detailed profile of our prototype high-penetration OCT was described previously. ${ }^{21}$ This OCT is a swept-source instrument with a scanning speed of 50,000 A-scans per second. Six $6 \mathrm{~mm}$ macula and disc regions were independently scanned using a horizontal fast raster protocol, and the A-scan density was 512 lines (horizontal) $\times 255$ lines (vertical). The scan time was 2.7 seconds. The center wavelength of the probe beam was 1060 nanometer (nm), and the bandwidth was $80 \mathrm{~nm}$ or more. The axial resolution was 11 microns in tissue. The long wavelength probe enables deep penetration to the choroid. Each magnification of OCT images was corrected by the axial length. Subfoveal choroidal thickness was measured on the macula image, and the choroidal thickness around the optic disc was measured on the disc image at the fovea and four locations ( $2 \mathrm{~mm}$ superior, temporal, inferior, and nasal locations to the center of the optic disc). The choroidal thickness was measured, according to the method described previously. $^{22,23}$ The choroidal thickness was defined as the distance between the hyper scattering line of the retinal pigment epithelium (RPE) and the chorio-scleral interface. The RPE and chorioscleral interface were clearly identified.

OCT images were obtained at about $3 \mathrm{pm}$, with the patient sitting to eliminate the effect of circadian variations on the choroidal thickness. . $^{54,25}$

\section{Surgical technique}

Two glaucoma surgery specialists (Y Otori, S Usui) performed all trabeculectomies. A $3.5 \times 3.5 \mathrm{~mm}$ scleral flap was created superotemporally or superonasally from the limbus; $0.04 \%$ mitomycin C was applied for 5 minutes. The scleral flap was sutured using 10-0 nylon. Blebs were managed by laser suture lysis, which promoted filtration and bleb formation after trabeculectomy. Optimal visualization of the nylon suture was achieved with a Blumenthal lens (Volk Optical Inc, Mentor, OH, USA) or the Ocular Mandelkorn lens (Ocular Instruments Inc, Bellevue, WA, USA). Phacoemulsification was performed followed by intraocular lens implantation in the capsular bag. A phaco probe was inserted into the cornea temporally. Yellow-tinted hydrophobic soft acrylic lens (NS-60YG, Nidek Co, Ltd, Gamagori, Japan) was used for intraocular lens implantation. Topical treatments were performed after surgery. All patients were treated with Levofloxacin hydrate and Betamethasone sodium phosphate after trabeculectomy. Bromfenac sodium hydrate was also used for the patients after simultaneous cataract surgery.

\section{Other examinations}

After the OCT measurement, the axial length which was regarded as the distance from the corneal vertex to the RPE layer was measured, using partial optical coherence interferometry (IOL Master, Carl Zeiss Meditec, Dublin, CA, 
USA). Finally, the IOP was measured by Goldmann applanation tonometry under treatment with topical anesthesia.

\section{Statistical analysis}

The data were analyzed, using analysis of variance with the paired $t$-test. The relationships between the IOP, the axial length, and the choroidal thickness changes following trabeculectomy were evaluated by Pearson's correlation coefficient. Statistical analyses were performed using JMP version 9.0 (SAS Institute Inc, Cary, NC, USA). $P<0.05$ was considered statistically significant.

\section{Results}

\section{Patient demographic data}

Table 1 shows the demographic data from 14 subjects (nine men, five women; mean age, 65.0 \pm 8.7 years; range, 50-76). Eight subjects had primary open-angle glaucoma (POAG), and six subjects had secondary glaucoma. The choroidal thickness was analyzed in 14 of 14 subjects at the fovea, and in ten of 14 subjects around the optic disc. Four subjects were excluded from measurement of the peripapillary area because of poor image quality or poor visual fixation.

\section{IOP and axial length after trabeculectomy}

Fluctuations in IOP and axial length in 14 patients with glaucoma were compared 1 day before and 6 days after trabeculectomy. The mean IOP in the trabeculectomy eyes decreased significantly from $26.6 \pm 7.6 \mathrm{mmHg}$ to $7.2 \pm 2.6 \mathrm{mmHg}$ postoperatively $(P<0.0001$, by paired $t$-test). There was no significant difference in the mean IOP in the fellow eyes, before and after trabeculectomy $(P=0.22$, by paired $t$-test, $17.0 \pm 4.7 \mathrm{mmHg}$ preoperatively and $15.5 \pm 6.1 \mathrm{mmHg}$ postoperatively). The mean axial length in the eyes that underwent trabeculectomy decreased significantly from $25.12 \pm 1.42 \mathrm{~mm}$ to $24.86 \pm 1.43 \mathrm{~mm}(P=0.001$, by paired $t$-test). The mean axial length in the fellow eyes did not differ significantly, before and after trabeculectomy $(P=0.62$, by paired $t$-test, $25.00 \pm 1.52 \mathrm{~mm}$, preoperatively;

Table I Demographic data

\begin{tabular}{ll}
\hline Parameter & $\mathbf{n}$ \\
\hline Number of subjects & 14 \\
Men/women & $(9 / 5)$ \\
Age (years, mean \pm SD) & $65.0 \pm 8.7$ \\
Glaucoma type & \\
$\quad$ POAG subjects & 8 \\
Secondary glaucoma subjects & 6 \\
\hline
\end{tabular}

Abbreviations: SD, standard deviation; POAG, primary open-angle glaucoma.
$24.99 \pm 1.52 \mathrm{~mm}$, postoperatively). The decreases in IOP were correlated positively with shortening of the axial length in eyes that underwent trabeculectomy $\left(R^{2}=0.41, P=0.013\right.$, by Pearson's correlation coefficient) (Figure 1).

\section{Choroidal thicknesses after trabeculectomy}

Table 2 shows the changes in the mean choroidal thickness at the fovea and $2 \mathrm{~mm}$ superior, temporal, inferior, and nasal to the center of the optic disc before and after trabeculectomy in the eyes that underwent surgery and the fellow eyes.

The mean choroidal thickness at the fovea in eyes treated with trabeculectomy significantly increased postoperatively ( $P<0.0001$, by paired $t$-test); however, in the fellow eyes, there was no significant difference before and after surgery ( $P=0.27$, by paired $t$-test). The mean choroidal thicknesses around the optic disc also significantly increased superiorly, temporally, inferiorly, and nasally $(P<0.01$, for all comparisons by paired $t$-test) after trabeculectomy in the eyes that underwent surgery; the choroidal thicknesses in the fellow eyes in the same locations did not differ significantly, before and after trabeculectomy. The changes in subfoveal choroidal thickness were similar between POAG and secondary glaucoma in the eyes that underwent trabeculectomy $(P=0.004$ for POAG; $P=0.048$ for secondary glaucoma, by paired $t$-test).

The increase in the choroidal thickness at the fovea was not correlated with either decreases in IOP or shortening of the axial length $\left(R^{2}=0.08, P=0.32\right.$ for IOP reduction; $R^{2}=0.1, P=0.27$ for shortening of the axial length, by Pearson's correlation coefficient). Decrease in IOP was correlated with the increases in the choroidal thickness around the optic disc inferiorly and nasally $\left(R^{2}=0.42, P=0.04\right.$ for inferiorly; $R^{2}=0.44, P=0.035$ for nasally, by Pearson's correlation coefficient), but not superiorly and temporally around the optic disc $\left(R^{2}=0.025, P=0.65\right.$ for superiorly; $R^{2}=0.36, P=0.06$ for temporally, by Pearson's correlation coefficient) (Figure 1 and Table 3 ).

\section{Sum of the axial length and subfoveal choroidal thicknesses after trabeculectomy}

The sum of the axial length and subfoveal choroidal thickness in 14 eyes that underwent trabeculectomy significantly decreased after surgery from $25.32 \pm 1.41 \mathrm{~mm}$ to $25.11 \pm 1.42 \mathrm{~mm}(P=0.004$, by paired $t$-test $)$; however, in the fellow eyes there was no significant difference before and after surgery ( $P=0.83$, by paired $t$-test, $25.24 \pm 1.51 \mathrm{~mm}$ preoperatively; $25.24 \pm 1.53 \mathrm{~mm}$ postoperatively) (Table 4). 

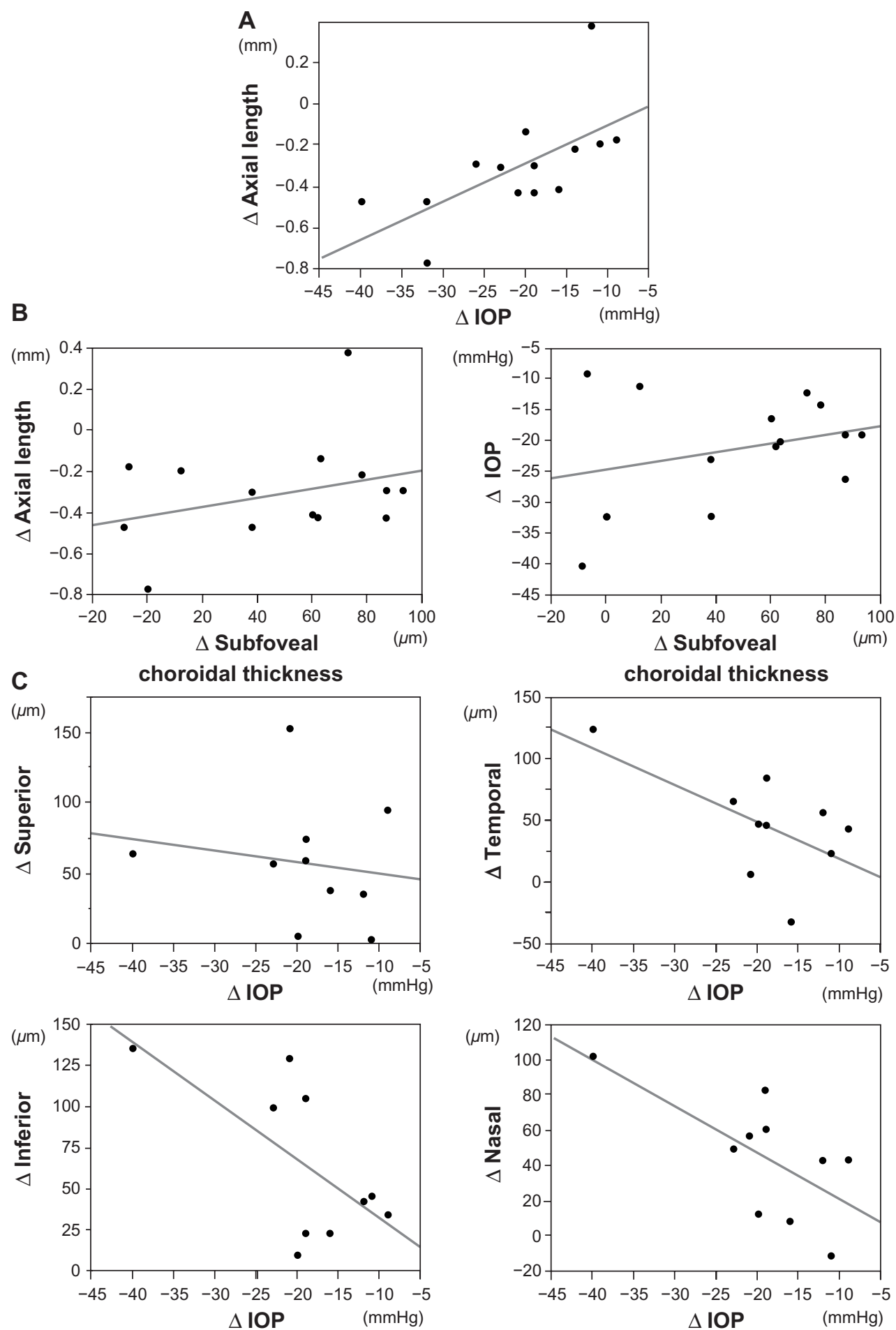

Figure I Relationships between intraocular pressure, axial length, and choroidal thickness changes following trabeculectomy.

Notes: (A) The decreases in IOP were correlated positively with shortening of the axial length. (B) The increase in the choroidal thickness at the fovea was not correlated with either decreases in IOP or shortening of the axial length. (C) The increase in subfoveal choroidal thickness was not correlated with either decreases in IOP or shortening of the axial length. Decrease in IOP was correlated with the increases in the choroidal thickness around the optic disc inferiorly and nasally, but not superiorly and temporally. $\Delta$, changes following trabeculectomy.

Abbreviation: IOP, intraocular pressure.

\section{Discussion}

Previous studies have suggested that the axial length shortens as a result of reductions in IOP after trabeculectomy during the early postoperative period. ${ }^{25}$ In the current study, the changes in IOP were correlated positively with the changes in axial length after trabeculectomy. Németh and Horóczi reported decreased axial length and increased thickness and volume of the ocular wall after trabeculectomy. ${ }^{25}$ The 
Table 2 Intraocular pressure, axial length, and choroidal thickness before and after trabeculectomy

\begin{tabular}{|c|c|c|c|c|c|c|c|}
\hline & \multirow[t]{2}{*}{$\mathbf{N}$} & \multicolumn{3}{|c|}{ Trabeculectomy eye } & \multicolumn{3}{|l|}{ Fellow eye } \\
\hline & & $\begin{array}{l}\text { Preoperatively } \\
(\text { mean } \pm \text { SD) }\end{array}$ & $\begin{array}{l}\text { Postoperatively } \\
\text { (mean } \pm \text { SD) }\end{array}$ & $P$-value & $\begin{array}{l}\text { Preoperatively } \\
(\text { mean } \pm \text { SD) }\end{array}$ & $\begin{array}{l}\text { Postoperatively } \\
\text { (mean } \pm \text { SD) }\end{array}$ & $P$-value \\
\hline IOP & 14 & $26.6 \pm 7.6$ & $7.2 \pm 2.6$ & $<0.000 I^{*}$ & $17 \pm 4.7$ & $15.5 \pm 6.1$ & 0.22 \\
\hline Axial length & 14 & $25.12 \pm 1.42$ & $24.86 \pm 1.43$ & $<0.00 I^{*}$ & $25 \pm 1.52$ & $24.99 \pm 1.52$ & 0.62 \\
\hline \multicolumn{8}{|l|}{ Choroidal thickness } \\
\hline Fovea & 14 & $206 \pm 64$ & $254 \pm 64$ & $<0.000 I^{*}$ & $242 \pm 51$ & $245 \pm 62$ & 0.27 \\
\hline Superior to disc & 10 & $164 \pm 50$ & $222 \pm 49$ & $<0.0 I^{*}$ & $189 \pm 57$ & $187 \pm 66$ & 0.78 \\
\hline Temporal to disc & 10 & $140 \pm 70$ & $|87 \pm 6|$ & $<0.0 I^{*}$ & $154 \pm 56$ & $161 \pm 57$ & 0.06 \\
\hline Inferior to disc & 10 & $123 \pm 50$ & $188 \pm 57$ & $<0.0 I^{*}$ & $117 \pm 39$ & $|3| \pm 44$ & 0.09 \\
\hline Nasal to disc & 10 & $159 \pm 72$ & $204 \pm 67$ & $<0.01 *$ & $|7| \pm 64$ & $181 \pm 63$ & 0.27 \\
\hline
\end{tabular}

Note: $* P<0.05$

Abbreviations: $\mathrm{N}$, number; SD, standard deviation; IOP, intraocular pressure.

changes in axial length should be affected by the anatomic and physiologic characteristics of the outside tissues, such as the choroid and the sclera. We found that the subfoveal choroidal thickness increased significantly after trabeculectomy, compared with preoperatively. However, the changes in the subfoveal choroidal thickness were not correlated with changes in the IOP. One explanation may be the individual variations in the choroidal thickness. The choroid is thin in myopic eyes and in older age. ${ }^{26}$ We also found that the choroid at the fovea and around the optic disc in young highly myopic patients with normal-tension glaucoma was thinner compared with the choroid in age- and axial length-matched healthy subjects. ${ }^{22}$ Chakraborty et al recently reported a positive association between variations in IOP and axial length and a negative association between axial length and choroidal thickness during 12 hours of observation over two consecutive days. ${ }^{5}$ Our findings suggest that the change in choroidal thickness after filtering surgery-induced variations in IOP might differ to those observed in normal diurnal variations in choroidal thickness. It needs to be clarified how the circadian fluctuations differed between subjects and what the significance of this is for the current study. Our recent noteworthy finding was that the amplitudes of circadian fluctuations in subfoveal choroidal thickness differed among the subjects. ${ }^{24}$ The average mean circadian fluctuation was about 33 microns, and the largest fluctuation was 65 microns. The smallest fluctuation in that study was 8 microns. In the current study, the IOP, axial length, and choroidal thickness were measured at $3 \mathrm{pm}$ to eliminate some factors that are affected by these circadian changes.

Diurnal fluctuations of the choroidal thickness are small, stable, and consistent, whereas the fluctuations in the choroidal thickness resulting from trabeculectomy may be large and acute, because the decrease in IOP during trabeculectomy occurs within a very short time. The decrease in IOP following trabeculectomy would cause changes in uveoscleral outflow. It is well-known that some complications affect the choroid during and after trabeculectomy, ie, maculopathy, choroidal effusion, choroidal hemorrhage, and expulsive hemorrhage resulting from hypotony. ${ }^{27-31} \mathrm{~A}$ choroidal or expulsive hemorrhage especially is a particularly devastating complication that usually results from a sudden reduction in IOP with the rupture of a large choroidal vessel. We excluded subjects with these complications that occurred as a result of a substantial decrease in IOP after trabeculectomy. Increases in choroidal thickness resulting from a sudden decrease in IOP during trabeculectomy might be related to these choroidal complications.

Abnormalities of the ocular circulation, such as loss of autoregulation and a larger diurnal fluctuation of ocular blood flow in patients with glaucoma, have been reported; $;^{13,32-36}$ some investigators have reported increased ocular blood flow or ocular perfusion pressure after trabeculectomy. ${ }^{37,38} \mathrm{~A}$ significant increase in the optic nerve head blood flow also was observed after trabeculectomy. ${ }^{39-41}$ In fact, we found increases

Table 3 Relationships between intraocular pressure, axial length and choroidal thickness changes following trabeculectomy

\begin{tabular}{|c|c|c|c|c|}
\hline \multirow[t]{2}{*}{ Factor } & \multirow[t]{2}{*}{$\mathbf{N}$} & \multicolumn{3}{|l|}{$\Delta$ IOP } \\
\hline & & Coefficient & $R^{2}$ & $P$-value \\
\hline$\Delta$ Axial length & 14 & 0.018 & 0.41 & $0.013^{*}$ \\
\hline \multirow[t]{2}{*}{ Factor } & \multirow[t]{2}{*}{$\mathbf{N}$} & \multicolumn{3}{|c|}{$\Delta$ Subfoveal choroidal thickness } \\
\hline & & Coefficient & $R^{2}$ & $P$-value \\
\hline$\Delta \mathrm{IOP}$ & 14 & 0.069 & 0.08 & 0.32 \\
\hline$\Delta$ Axial length & 14 & 0.0022 & 0.1 & 0.27 \\
\hline \multirow{2}{*}{$\begin{array}{l}\Delta \text { Choroidal thickness } \\
\text { around the optic disc }\end{array}$} & \multirow[t]{2}{*}{$\mathbf{N}$} & \multicolumn{3}{|l|}{$\Delta$ IOP } \\
\hline & & Coefficient & $R^{2}$ & $P$-value \\
\hline Superior & 10 & -0.8 & 0.025 & 0.65 \\
\hline Temporal & 10 & -2.97 & 0.36 & 0.06 \\
\hline Inferior & 10 & -3.56 & 0.42 & $0.04 *$ \\
\hline Nasal & 10 & -2.61 & 0.44 & $0.035^{*}$ \\
\hline
\end{tabular}

Note: $* P<0.05 . \Delta$, changes following trabeculectomy.

Abbreviation: IOP, intraocular pressure. 
Table 4 Total sum of axial length and subfoveal choroidal thickness before and after trabeculectomy

\begin{tabular}{|c|c|c|c|c|c|}
\hline \multicolumn{3}{|c|}{ Trabeculectomy eye } & \multicolumn{3}{|l|}{ Fellow eye } \\
\hline $\begin{array}{l}\text { Preoperatively } \\
\text { (mean } \pm \text { SD) } \mathrm{mm}\end{array}$ & $\begin{array}{l}\text { Postoperatively } \\
\text { (mean } \pm \text { SD) } \mathrm{mm}\end{array}$ & $P$-value & $\begin{array}{l}\text { Preoperatively } \\
\text { (mean } \pm \text { SD) } \mathrm{mm}\end{array}$ & $\begin{array}{l}\text { Postoperatively } \\
\text { (mean } \pm \text { SD) } \mathrm{mm}\end{array}$ & $P$-value \\
\hline $25.32 \pm 1.4 I$ & $25.11 \pm 1.42$ & $0.004^{*}$ & $25.24 \pm 1.51$ & $25.24 \pm 1.53$ & 0.83 \\
\hline
\end{tabular}

Note: $* P<0.05$.

Abbreviation: SD, standard deviation.

in choroidal thickness around the optic disc in the eyes that underwent trabeculectomy. It is uncertain how the anatomic choroidal thickening and blood flow are related, but trabeculectomy may be associated with retrobulbar hemodynamic changes. Lee et al recently reported anterior movement of the laminar cribrosa and thickening of the laminar cribrosa and prelaminar tissue after a reduction in IOP, resulting from trabeculectomy in glaucomatous eyes ${ }^{42}$ Sigal et al studied the laminar cribrosa deformation and the scleral canal expansion associated with acute changes in IOP in monkey eyes. ${ }^{43}$ They showed that combinations of the laminar cribrosa deformation and the scleral canal expansion were classified to some cases by lamina or scleral thickness and stiffness. Thus, the IOP fluctuations caused changes in the deep structures, ie, the laminar tissue, choroid, and sclera. In fact, the current study showed that the sum of the axial length and subfoveal choroidal thickness decreases after trabeculectomy, which may affect the scleral stiffness.

In conclusion, the current study showed that the axial length shortened, and the choroidal thicknesses at the fovea and peripapillary area increased as a result of decreases in IOP reduction during the early period after trabeculectomy. The sum of the axial length and subfoveal choroidal thickness decreased after surgery.

\section{Acknowledgments}

This work was presented at the Association for Research in Vision and Ophthalmology-International Society for Imaging in the Eye/Imaging Conference in 2012.

\section{Disclosure}

YY received financial support from Topcon Corporation (Tokyo, Japan) and a grant from the Japan Science and Technology Agency. The other authors report no conflicts of interest in this work.

\section{References}

1. Nickla DL, Wildsoet C, Wallman J. The circadian rhythm in intraocular pressure and its relation to diurnal ocular growth changes in chicks. Exp Eye Res. 1998;66(2):183-193.

2. Nickla DL, Wildsoet CF, Troilo D. Diurnal rhythms in intraocular pressure, axial length, and choroidal thickness in a primate model of eye growth, the common marmoset. Invest Ophthalmol Vis Sci. 2002;43(8): 2519-2528.
3. Wilson LB, Quinn GE, Ying G, Francis EL, Schmid G, Lam A, et al. The relation of axial length and intraocular pressure fluctuation in human eyes. Invest Ophthalmol Vis Sci. 2006;47(5):1778-1784.

4. Read SA, Collins MJ, Iskander DR. Diurnal variation of axial length, intraocular pressure, and anterior eye biometrics. Invest Ophthalmol Vis Sci. 2008;49(7):2911-2918.

5. Chakraborty R, Read SA, Collins MJ. Diurnal variations in axial length, choroidal thickness, intraocular pressure, and ocular biometrics. Invest Ophthalmol Vis Sci. 2011;52(8):5121-5129.

6. Wallman J, Wildsoet $\mathrm{C}, \mathrm{Xu}$ A, et al. Moving the retina: choroidal modulation of refractive state. Vision Res. 1995;35(1):37-50.

7. Nickla $D$. The phase relationships between the diurnal rhythms in axial length and choroidal thickness and the association with ocular growth rate in chicks. J Comp Physiol A Neuroethol Sens Neural Behav Physiol. 2006;192(4):399-407.

8. Brown JS, Flitcroft DI, Ying GS, et al. In vivo human choroidal thickness measurements: evidence for diurnal fluctuations. Invest Ophthalmol Vis Sci. 2009;50(1):5-12.

9. Suzuki Y, Iwase A, Araie M, et al. Risk factors for open-angle glaucoma in a Japanese population: the Tajimi Study. Ophthalmology. 2006;113(9):1613-1617.

10. Mitchell P, Hourihan F, Sandbach J, Wang JJ. The relationship between glaucoma and myopia: the Blue Mountains Eye Study. Ophthalmology. 1999;106(10):2010-2015.

11. Xu L, Wang Y, Wang S, Wang Y, Jonas JB. High myopia and glaucoma susceptibility the Beijing Eye Study. Ophthalmology. 2007;114(2): 216-220.

12. Oku Y, Oku H, Park M, et al. Long axial length as risk factor for normal tension glaucoma. Graefes Arch Clin Exp Ophthalmol. 2009;247(6): 781-787.

13. Duijm HF, van den Berg TJ, Greve EL. A comparison of retinal and choroidal hemodynamics in patients with primary open-angle glaucoma and normal-pressure glaucoma. Am J Ophthalmol. 1997;123(5): 644-656.

14. Usui S, Ikuno Y, Miki A, Matsushita K, Yasuno Y, Nishida K. Evaluation of the choroidal thickness using high-penetration optical coherence tomography with long wavelength in highly myopic normal-tension glaucoma. Am J Ophthalmol. 2012;153(1):10-16.

15. Hirooka K, Fujiwara A, Shiragami C, Baba T, Shiraga F. Relationship between progression of visual field damage and choroidal thickness in eyes with normal-tension glaucoma. Clin Experiment Ophthalmol. 2012;40(6):576-582.

16. Hirooka K, Tenkumo K, Fujiwara A, Baba T, Sato S, Shiraga F. Evaluation of peripapillary choroidal thickness in patients with normaltension glaucoma. BMC Ophthalmol. 2012;12:29.

17. Cashwell LF, Martin CA. Axial length decrease accompanying successful glaucoma filtration surgery. Ophthalmology. 1999;106(12): 2307-2311.

18. Uretmen O, Ateş H, Andaç K, Deli B. Axial length changes accompanying successful nonpenetrating glaucoma filtration surgery. Ophthalmologica. 2003;217(3):199-203.

19. Francis BA, Wang M, Lei H, et al. Changes in axial length following trabeculectomy and glaucoma drainage device surgery. Br JOphthalmol. 2005;89(1):17-20.

20. Leydolt C, Findl O, Drexler W. Effects of change in intraocular pressure on axial eye length and lens position. Eye (Lond). 2008;22(5): 657-661. 
21. Yasuno Y, Hong Y, Makita S, et al. In vivo high-contrast imaging of deep posterior eye by 1-microm swept source optical coherence tomography and scattering optical coherence angiography. Opt Express. 2007;15(10):6121-6139.

22. Usui S, Ikuno Y, Miki A, Matsushita K, Yasuno Y, Nishida K. Evaluation of the choroidal thickness using high-penetration optical coherence tomography with long wavelength in highly myopic normaltension glaucoma. Am J Ophthalmol. 2012;153(1):10-16.

23. Tan CS, Ouyang Y, Ruiz H, Sadda SR. Diurnal variation of choroidal thickness in normal, healthy subjects measured by spectral domain optical coherence tomography. Invest Ophthalmol Vis Sci. 2012;53(1): 261-266.

24. Usui S, Ikuno Y, Akiba M, et al. Circadian changes in subfoveal choroidal thickness and the relationship with circulatory factors in healthy subjects. Invest Ophthalmol Vis Sci. 2012;53(4): 2300-2307.

25. Németh J, Horóczi Z. Changes in the ocular dimensions after trabeculectomy. Int Ophthalmol. 1992;16(4-5):355-357.

26. Ikuno Y, Kawaguchi K, Nouchi T, Yasuno Y. Choroidal thickness in healthy Japanese subjects. Invest Ophthalmol Vis Sci. 2010;51(4): 2173-2176.

27. Dellaporta A. Fundus changes in postoperative hypotony. Am J Ophthalmol. 1955;40(6):781-785.

28. Brubaker RF, Pederson JE. Ciliochoroidal detachment. Surv Ophthalmol. 1983;27(5):281-289.

29. Schubert HD. Postsurgical hypotony: relationship to fistulization, inflammation, chorioretinal lesions, and the vitreous. Surv Ophthalmol. 1996;41(2):97-125.

30. Chu TG, Green RL. Suprachoroidal hemorrhage. Surv Ophthalmol. 1999;43(6):471-486

31. Speaker MG, Guerriero PN, Met JA, Coad CT, Berger A, Marmor M. A case-control study of risk factors for intraoperative suprachoroidal expulsive hemorrhage. Ophthalmology. 1991;98(2):202-209.

32. Tielsch JM, Katz J, Sommer A, Quigley HA, Javitt JC. Hypertension, perfusion pressure, and primary open-angle glaucoma. A populationbased assessment. Arch Ophthalmol. 1995;113(2):216-221.
33. Flammer J, Orgül S. Optic nerve blood-flow abnormalities in glaucoma. Prog Retin Eye Res. 1998;17(2):267-289.

34. Pemp B, Georgopoulos M, Vass C, et al. Diurnal fluctuation of ocular blood flow parameters in patients with primary open-angle glaucoma and healthy subjects. Br J Ophthalmol. 2009;93(4):486-491.

35. Fuchsjäger-Mayrl G, Wally B, Georgopoulos M, et al. Ocular blood flow and systemic blood pressure in patients with primary open-angle glaucoma and ocular hypertension. Invest Ophthalmol Vis Sci. 2004;45(3): 834-839.

36. Kochkorov A, Gugleta K, Katamay R, Flammer J, Orgul S. Short-term variability of systemic blood pressure and submacular choroidal blood flow in eyes of patients with primary open-angle glaucoma. Graefes Arch Clin Exp Ophthalmol. 2010;248(6):833-837.

37. James CB. Effect of trabeculectomy on pulsatile ocular blood flow. Br J Ophthalmol. 1994;78(11):818-822.

38. Berisha F, Schmetterer K, Vass C, et al. Effect of trabeculectomy on ocular blood flow. Br J Ophthalol. 2005;89(2):185-188.

39. Tamaki Y, Araie M, Hasegawa T, Nagahara M. Optic nerve head circulation after intraocular pressure reduction achieved by trabeculectomy. Ophthalmology. 2001;108(3):627-632.

40. Hafez AS, Bizzarro RL, Rivard M, Lesk MR. Changes in optic nerve head blood flow after therapeutic intraocular pressure reduction in glaucoma patients and ocular hypertensives. Ophthalmology. 2003;110(1): 201-210.

41. Lesk MR, Hafez AS, Descovich D. Relationship between central corneal thickness and changes of optic nerve head topography and blood flow after intraocular pressure reduction in open-angle glaucoma and ocular hypertension. Arch Ophthalmol. 2006;124(11): 1568-1572.

42. Lee EJ, Kim TW, Weinreb RN. Reversal of lamina cribrosa displacement and thickness after trabeculectomy in glaucoma. Ophthalmology. 2012;119(7):1359-1366.

43. Sigal IA, Yang H, Roberts MD, Burgoyne CF, Downs JC. IOP-induced lamina cribrosa displacement and scleral canal expansion: an analysis of factor interactions using parameterized eye-specific models. Invest Ophthalmol Vis Sci. 2011;52(3):1896-1907.
Clinical Ophthalmology

\section{Publish your work in this journal}

Clinical Ophthalmology is an international, peer-reviewed journal covering all subspecialties within ophthalmology. Key topics include: Optometry; Visual science; Pharmacology and drug therapy in eye diseases; Basic Sciences; Primary and Secondary eye care; Patient Safety and Quality of Care Improvements. This journal is indexed on

\section{Dovepress}

PubMed Central and CAS, and is the official journal of The Society of Clinical Ophthalmology (SCO). The manuscript management system is completely online and includes a very quick and fair peer-review system, which is all easy to use. Visit http://www.dovepress.com/ testimonials.php to read real quotes from published authors. 